\title{
Management of Acute Necrotizing Pancreatitis
}

\author{
Mohamed Amjad Jamaluddin ${ }^{1} \cdot$ Kamal Kataria $^{1}$
}

Received: 15 December 2015 / Accepted: 10 February 2016/Published online: 17 February 2016

(C) Association of Surgeons of India 2016

\section{Dear Sir,}

We read the article entitled "Surgery in Pancreatic Necrosis-Challenges and Outcomes in an Industrial Hospital" by Ashok Chattoraj et al. in the Indian Journal of Surgery [1]. The authors have divided the management of acute severe necrotizing pancreatitis into conservative for most patients and surgical in those who are refractory to the initial medical management. In this era of endoscopists, intensivists, interventional radiologists, medical microbiologists, and minimal access surgeons, the management of acute necrotizing pancreatitis has slipped away from the sole hands of surgeons to the multidisciplinary teambased approach of an ICU team.

The landmark Dutch "PANTER trial" needs a mention in this context. This superiority hypothesis-based randomized controlled trial was conducted in 20 hospitals of the Dutch Acute Pancreatitis Study Group. This trial concluded that a minimally invasive "step up approach" as compared to the open necrosectomy reduced the morbidity and mortality among patients with necrotizing pancreatitis. In contrast to open necrosectomy, which aims at complete removal of necrosum, step-up approach consisted of percutaneous drainage followed, if necessary, by minimally invasive retroperitoneal necrosectomy, which targets damage control of the source of infection [2]. The trial speculates that the drainage of infected fluid content is enough

Mohamed Amjad Jamaluddin

amjad96@rocketmail.com

1 Department of Surgical Disciplines, All India Institute of Medical Sciences, New Delhi, India and the pancreatic necrosis can be left in situ similar to a necrotizing pancreatitis without infection. The stress of laparotomy is too large to be tolerated by a patient with acute necrotizing pancreatitis who is at the verge of multiorgan dysfunction. In such patients, a minimally invasive technique provokes less surgical trauma thereby decreasing the overall morbidity and mortality. In the long term, the incidence of new-onset diabetes and pancreatic insufficiency which was higher in open necrosectomy group might be due to the fact that viable pancreas might be removed in an attempt to achieve complete debridement of the necrosum. Most of the minimally invasive procedures can be attempted in the ICU bed itself thereby alleviating the need to shift the sick patient to the operating theatre [2]. This trial has been followed by other trials across the world providing similar results. The different minimally invasive approaches are either in the form of percutaneous drainage (using a drain inserted transabdominal or retroperitoneally under fluoroscopic guidance) or endoscopic drainage (through the posterior wall of stomach) of the infected fluid. After an interval of $72 \mathrm{~h}$, in case of no clinical improvement, minimally invasive necrosectomy via retroperitoneum (VARD—videoassisted retroperitoneal debridement) is performed. Open necrosectomy is only indicated if there is no clinical improvement $72 \mathrm{~h}$ after VARD [3].

Thus, the management of acute necrotizing pancreatitis has changed downright with this trial with the onus of treating these patients transferred to intensivists with all others playing a very important role.

\section{Compliance with Ethical Standards}

Conflict of Interest The authors declare that they have no conflict of interest. 


\section{References}

1. Chattoraj A, Kumar S (2015) Surgery in pancreatic necrosis - challenges and outcomes in an industrial hospital. Indian J Surg. http:/ link.springer.com/10.1007/s12262-015-1395-4. Accessed 7 Dec 2015
2. van Santvoort HC, Besselink MG, Bakker OJ, Hofker HS, Boermeester MA, Dejong CH et al (2010) A step-up approach or open necrosectomy for necrotizing pancreatitis. N Engl J Med 362(16):1491-1502

3. Pezzilli R, Zerbi A, Campra D, Capurso G, Golfieri R, Arcidiacono PG et al (2015) Consensus guidelines on severe acute pancreatitis. Dig Liver Dis 47(7):532-543 